\title{
Physical activity assessment and health outcomes in old age: how valid are dose-response relationships in epidemiologic studies?
}

\author{
Katharina Meyer • Christian Stolz • Christoph Rott • \\ Kurt Laederach-Hofmann
}

Received: 6 August 2008 / Accepted: 2 January 2009/ Published online: 13 March 2009

(C) European Group for Research into Elderly and Physical Activity (EGREPA) 2009

\begin{abstract}
In this systematic review the validity of the dose-response relationships between physical activity (PA) and energy expenditure (EE) on defined health outcomes (cardio- and cerebrovascular morbidity and mortality, cancer) for the elderly is questioned. Medline, Cochrane, and EMBASE databases were reviewed for epidemiological longitudinal studies in populations aged $60+$ for the years 1985-2007. Although most of the 18 identified studies generally demonstrated an inverse dose-response relationship between PA and EE level with morbidity and mortality, the range of dose-responses was remarkably broad. The nature of the dose-response relationship remained unclear. PA questionnaires - even those constructed for the elderly - do not cover the extremely diverse aspects of age-specific PA behavior and modes of muscular activity. Only non-age-specific tables had been used to estimate the EE in the elderly. Direct measurements of EE were limited. The results have implications for the interpretation of the dose-response relationships between PA and EE on defined health outcomes in old age.
\end{abstract}

Keywords Physical activity - Energy expenditure .

Dose-response relationship · Epidemiologic studies · Old age

\footnotetext{
K. Meyer $(\varangle)$

Swiss Health Observatory and Medical Faculty,

University of Bern,

2010 Neuchatel, Switzerland

e-mail: meyer.katharina@bluewin.ch

C. Stolz $\cdot$ K. Laederach-Hofmann

Department of Internal Medicine, University of Bern,

Bern, Switzerland

C. Rott

Institute of Gerontology, University of Heidelberg,

Heidelberg, Germany
}

\section{Introduction}

Increasing epidemiology literature reports an inverse doseresponse relationship between low- and/or moderateintensity physical activity (PA) and energy expenditure (EE) on disease-specific morbidity and mortality in adult populations. Epidemiologic studies of PA and health rely on the appropriateness and accuracy of the methods used to measure the PA and EE. Directly measured PA by accelerometer [34] and EE by the doubly labeled water technique (DLW) [32] are currently the objective methods of choice [30]. However, these techniques are generally too expensive to use in population-based studies. Therefore, self-reporting questionnaires are most frequently the method to assess PA. From measurements of PA frequency, intensity, and duration, the EE is estimated by using tables for the given physical activity $[1,2]$.

The aim of this review is to examine the validity of the dose-response relationships between PA and EE on healthrelated outcomes as reported for older populations in epidemiologic studies. From a geriatric point of view, the authors raise at least three concerns about the methods used to measure the PA and EE:

Firstly, the PA behavior of elderly people is different from that of younger adults. Depending on different determinants of PA behavior (e.g. physiological, psychological, social, and environmental), which may vary with age, older people may prefer: light or moderate instead of intense PA [4, 7]; habitual activity instead of sport activity; short irregular bursts of PA instead of regular, daily, or weekly session.

Secondly, questionnaires may not assess PA in older adults with the same accuracy as in younger adults. Accuracy of recalled information in the elderly may be affected by the irregularity and/or complexity of their PA 
habits. Older people who are consistently either regularly active or sedentary may be able to remember their activity habits precisely. On the contrary, people with PA patterns that fluctuate within days, weeks, or even months are less likely to remember accurately [4, 7]. Additionally, in recalling PA the elderly with declining cognition and memory may bias self-reported information on previous PA, particularly over long periods of time [12]. Finally, the underlying questionnaires are deficient in covering the entire spectrum of all the physical activities undertaken and the manner in which they are performed in the elderly.

Thirdly, although EE measurements such as $\mathrm{kcal} / \mathrm{h}$ or $\mathrm{kcal} /$ week, and METs have been used with older populations in health outcome studies, they may not have been designed or validated for that purpose. The same PA may be performed with a substantially lower level of EE in the elderly compared to younger adults. Consequently, existing reference tables of estimated EE that are based on PA information from populations with a wide spectrum in age $[1,2]$ may not reliably estimate the true EE of PA in old age.

These concerns prompted us to take a closer look at population-based observational studies which evaluate the dose-response of PA and selected health-related outcomes among populations aged $60+$. Particularly, we scrutinized the age-specific PA assessment and EE determination, and look for potential limitations to evaluating and interpreting the dose-response relationships.

\section{Material and methods}

\section{Studies of interest}

The comprehensive literature search was selectively restricted to studies published in English between January 1, 1985 and May 31, 2007. The types of studies considered were longitudinal observational (cohort studies, panel studies) and population-based case-control studies. Randomized controlled trials were excluded because they are usually restricted to (1) a relatively small sample size and (2) have too narrow sample characteristics compared to population-based studies. Our search was limited to studies which used primary health outcomes of morbidity and mortality for cardio- and cerebrovascular disease, cancer, and all-cause mortality. Participants had to be over 60 and living in community dwellings. Techniques to measure PA and EE applicable in everyday life were considered. Excluded were studies using laboratory procedures to measure EE (e.g. room calorimetry). Also excluded were studies which assessed PA by two levels only - when the one reference level was defined as "physical inactivity" or $\mathrm{EE}$ “ $<500 \mathrm{kcal} /$ week" (equal to no physical activity).
Search strategy

Search strategy, identification and selection of studies are shown in Fig. 1.

We searched Medline, Cochrane, and EMBASE databases. The following key words (single MESH) and text words in categories (a to d), were combined to identify all articles that evaluated dose-response relationships for selected health outcomes

(a) The elderly population

(b) Physical activity and/or energy expenditure

(c) Exercise, leisure activity, leisure time physical activity, recreational activity, housework

(d) Physical activity questionnaire, physical activity recall questionnaire, physical activity survey, physical activity record, physical activity diary, DLW, accelerometer, pedometer, and motion sensor

Additionally, the names of PA questionnaires specifically designed for older populations (e.g. Questionnaire d'Activite Physique Saint Etienne (QAPSE) [5]; Zutphen Physical Activity Questionnaire (Zutphen) [11] were entered into the electronic search system. Meta-analyses and systematic reviews were hand-checked to find additional studies. Again, these studies were screened for further appropriate references. A non-statistical descriptive approach was chosen to present the quality of the methods used in assessing PA behavior and EE in the elderly.

Identification of relevant studies

The authors identified a total of 193 potentially relevant studies (141 publications from the electronic search and 52 from the manual search), but 175 studies did not meet the above inclusion criteria so were excluded. The remaining 18 studies were all prospective cohort studies. In these studies 31,660 individuals were included. Median year of publication was 1998. The follow-up period ranged from 6 months [19] to 30 years [6] with an average of 8.1 years.

\section{Results and discussion}

The health outcomes assessed were all-cause mortality $(n=10)$; mortality from specific causes, cardiovascular, stroke, cancer $(n=3)$; mortality from coronary heart disease $(n=1)$; risk of coronary heart disease $(n=1)$; and prevalence of cardiovascular risk factors $(n=3)$. Sixteen of the 18 cohort studies provided data on an inverse dose-response relationship between PA and health outcomes as assessed. When low and/or moderate PA and EE levels were compared to high levels, there was a wide range of increase in mortality risk, 
Fig. 1 Search strategy, and identification and selection of studies

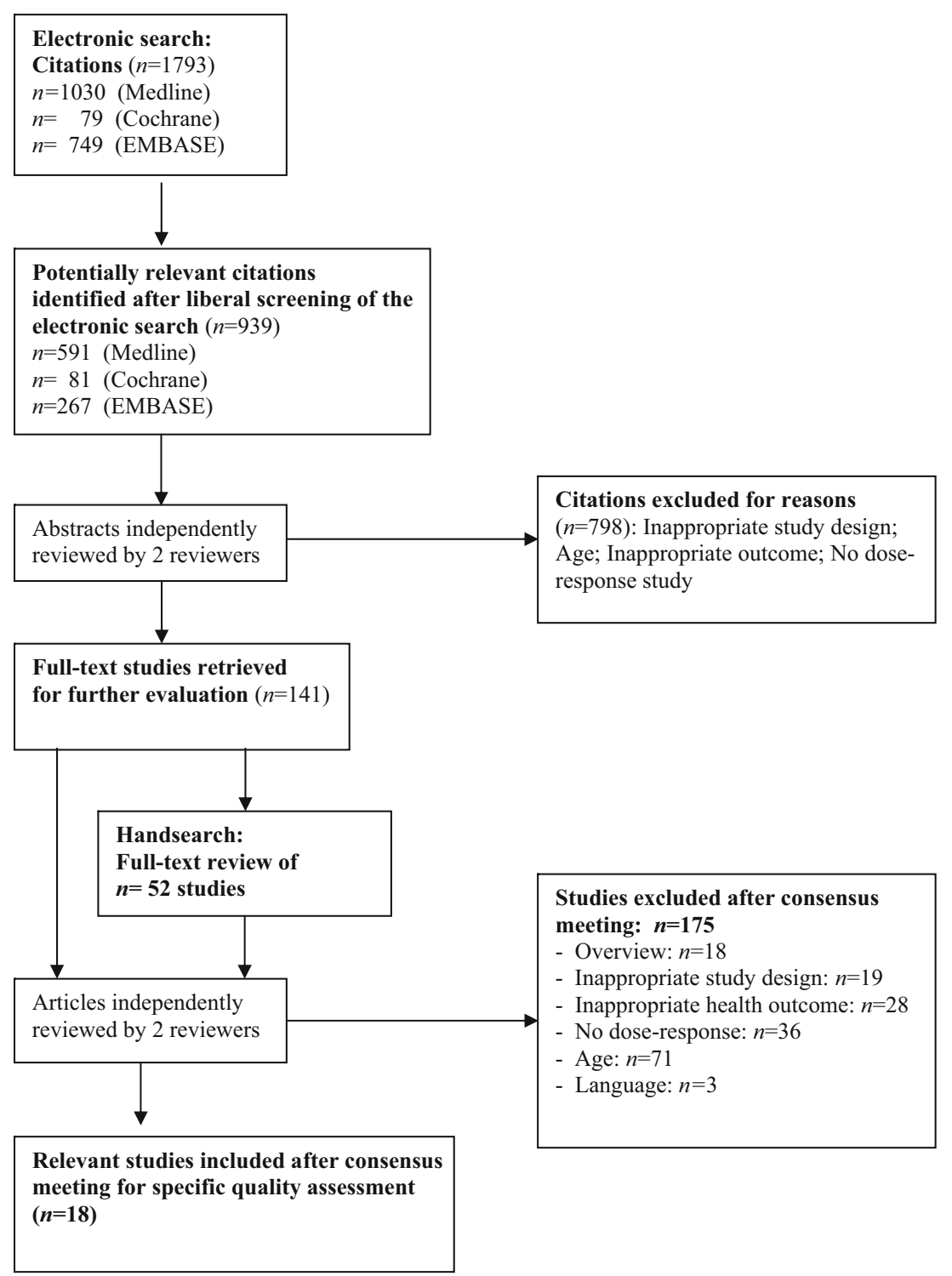

between $37 \%$ and $113 \%$ with an average of $75 \%$ [3, 18, 27, 29]. When comparing high PA level and low and/or moderate PA levels the mortality risk was reduced by a large range of $29-60 \%$ with an average of $50 \%[7,8,15,21,25,35]$. Looking at high versus moderate/low PA level, in men the average risk of mortality was also reduced for cardiovascular disease by $30 \%$ [7], and by $57 \%$ [3], while no significant effect was reported for cancer mortality [16]. Cardiovascular morbidity on average was more than double with low compared to high PA level [17]. Prevalence of coronary risk factors and PA level were either significantly associated [6, 35] or were not [19]. In only ten studies the health effect of PA and EE was adjusted for comorbidity, and in eight studies adjusted for age (Table 1, column 6). Overall, the wide range of results regarding the dose-response relationship is clearly evident. Additionally, the nature of the dose-response relationship remains unclear. This may be due to various methodological reasons.

In the 18 studies, questionnaires were given to assess PA. Additionally in five of the studies, EE was estimated (Table 1, columns 4 and 5) using published tables [1, 2]. In a single study the DLW method, accompanied with a questionnaire, was used [25]. Objective techniques such as accelerometer and pedometer use to determine EE for a defined PA had not been performed at all.

These reviews clearly showed that the methods used to assess PA behavior and pattern and EE varied enormously. None of the methods applied were entirely appropriate and sensitive enough to describe and measure both the PA behavior common among older populations and the EE of the PA as demonstrated in the following. 
Quality of the physical activity questionnaires

Among the 18 cohort studies, four PA questionnaires designed for older populations were administered: the QAPSE [5]; the Zutphen [11]; the Nottingham Questionnaire of Activity and Aging (NottQAA) [27], and the Elderly Nutrition and Health Survey Taiwan (ENHSTai) [21] (Table 1, column 3). However, only three of them have been validated among older populations $[5,11,21]$. These questionnaires have been applied in six of the 18 cohort studies (Table 1, column 3). Only two instruments (QAPSE and Zutphen) demonstrated an excellent relationship using the DLW method $[5,11]$ when tested in older people, indicating a strong direct validity which makes them appropriate for assessing PA and estimating EE in the elderly. Two questionnaires were designed with younger and older populations in mind (the modified Paffenbarger Physical Activity Questionnaire (modPPAQ), the Minnesota Leisure Time Physical Activity Questionnaire (modMLTPAQ)) and were applied in a modified version [15, 20]. Specific PA questionnaires for women - who represent the largest proportion of the elderly population - have not yet been developed.

For three questionnaires in the cohort studies (the modPPAQ; the QAPSE; the modMLTPAQ; Table 1, column 3) evidence for higher validity in measuring intensive PA rather than moderate or low-intensity PA has been reported [9]. It is not surprising that in many cohort studies the applied questionnaires focus on PA of moderate to vigorous intensity - which may be engaged in by only a small and highly select proportion of the older population - and ignore low-intensity PA. Because moderate and low PA was more prevalent among older people than vigorous PA $[4,6]$ the validity of measurements from the cohort studies, applied to the older population, in general may be limited.

\section{Modes of physical activity assessed}

The types of PA determined in the questionnaires varied greatly. Most studies assessed leisure time PA and sports as well as stair climbing and walking (Table 1, column 4). While structured walking (e.g. brisk and regular) was included, unstructured walking (e.g. being around on one's feet) as an essential dimension of PA in older age [26] was not considered in any single study. The self-reports of walking distance and speed of older people - which are more likely to differ from younger persons - have not yet been proven to be accurate and reliable.

Although domestic activities were shown to be a major source of PA in older people [22], only three studies (15\%) used instruments which explicitly asked for PA performed as housekeeping and home activities, (e.g. indoor and outdoor domestic home chores, grocery shopping, carrying, lifting, pushing objects, and unaccounted leisure time activities) [e.g. 27] (Table 1, column 4) which are especially relevant for older people. Lawler et al. (2002) reported that over two-thirds of the 60-79-year-old women assessed were at the recommended levels when domestic activities were included in the broad spectrum of PA.

\section{Dimensions of physical activity change with age}

Among the cohort studies, follow-up periods were up to 30 years (Table 1, column 2). Although age itself has little impact on interindividual differences in response to regular PA $[10,24]$, in the PA questionnaires applied to the aging population over a long follow-up period the dimensions of the PA which changes with advancing age and health has to be considered $[7,13]$. The Zutphen elderly study demonstrated that over a 10-year follow-up period the total time spent on PA in men aged $65-84$ decreased by $33 \%$ to $28 \mathrm{~min} /$ day. Time spent on cycling and gardening decreased from both an age and period effect. Time spent on walking remained stable, but its relative contribution to total time spent on PA increased with aging [7]. Among the questionnaires used, only the Zutphen [6] covered a broad spectrum of PA common in the elderly over a wide age range, yet did not involve domestic PA [6, 33, 35].

\section{Physical activity versus energy expenditure}

It is still unknown whether the EE measurements are sensitive or specific enough to accurately assess the agespecific features of PA. The highly valid DLW method applied only in one study [25] does provide EE on a PA over a certain time period. Yet, it does not provide detailed information on intensity, duration, and modes of the PA. Therefore, extrapolating EE from practice is difficult. In all other studies EE was calculated by MET scores for each activity from tables $[1,2]$. In these tables, reference values on EE are expressed as a ratio of working to resting metabolic rate.

However, tables have not been established by EE measurements explicitly obtained from older populations. In the elderly the total EE was shown to vary widely with body weight and activity behavior, while the resting metabolic rate was lower than in younger individuals [31, 36]. Thus, the validity of the working metabolic rate in older people estimated from tables may be compromised, and the actual dose-response relationship cannot be concluded (Table 1, columns 5 and 6).

Summary of results

This systematic review shows a general inverse doseresponse relationship between PA and EE on defined health 


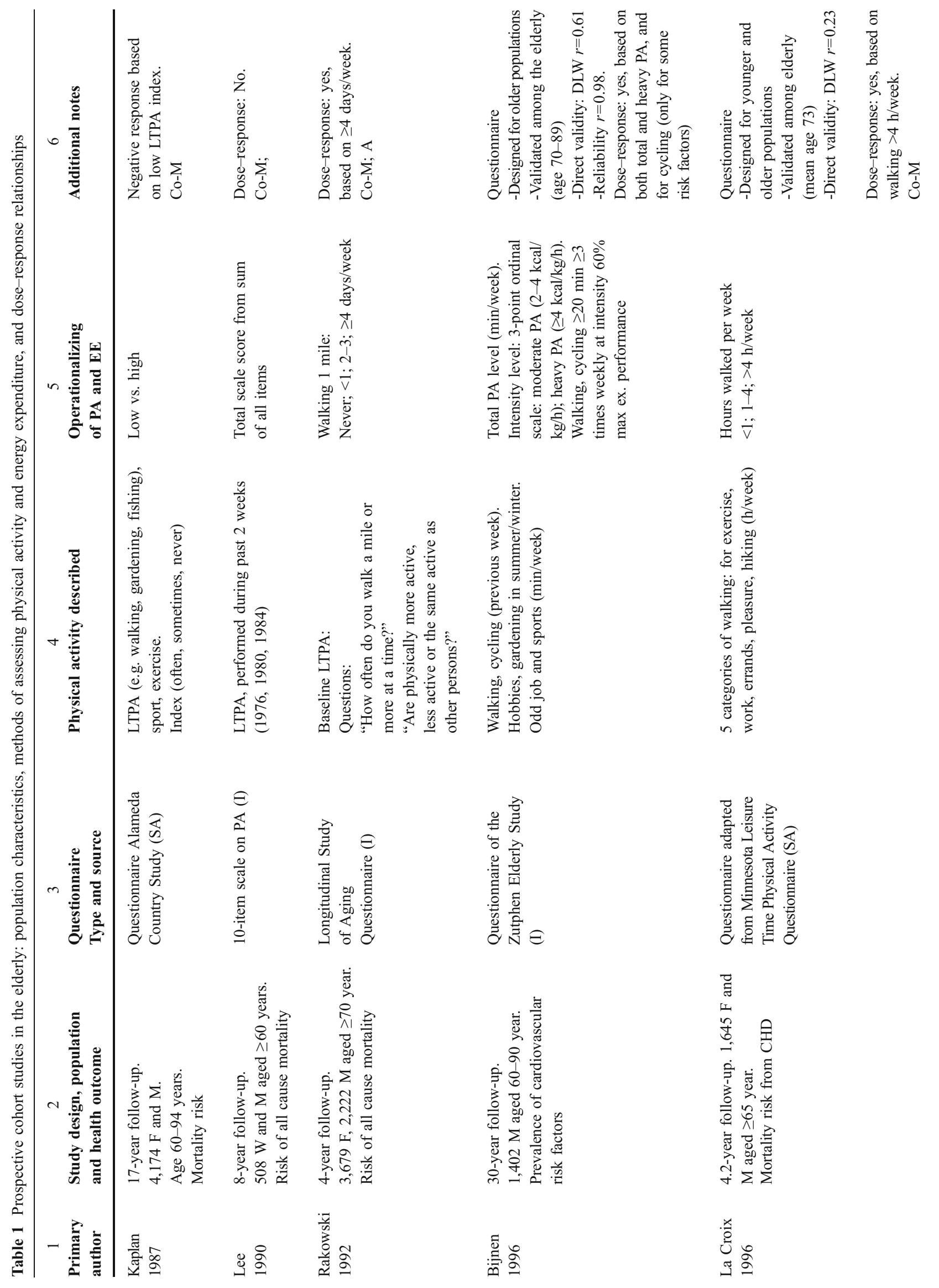




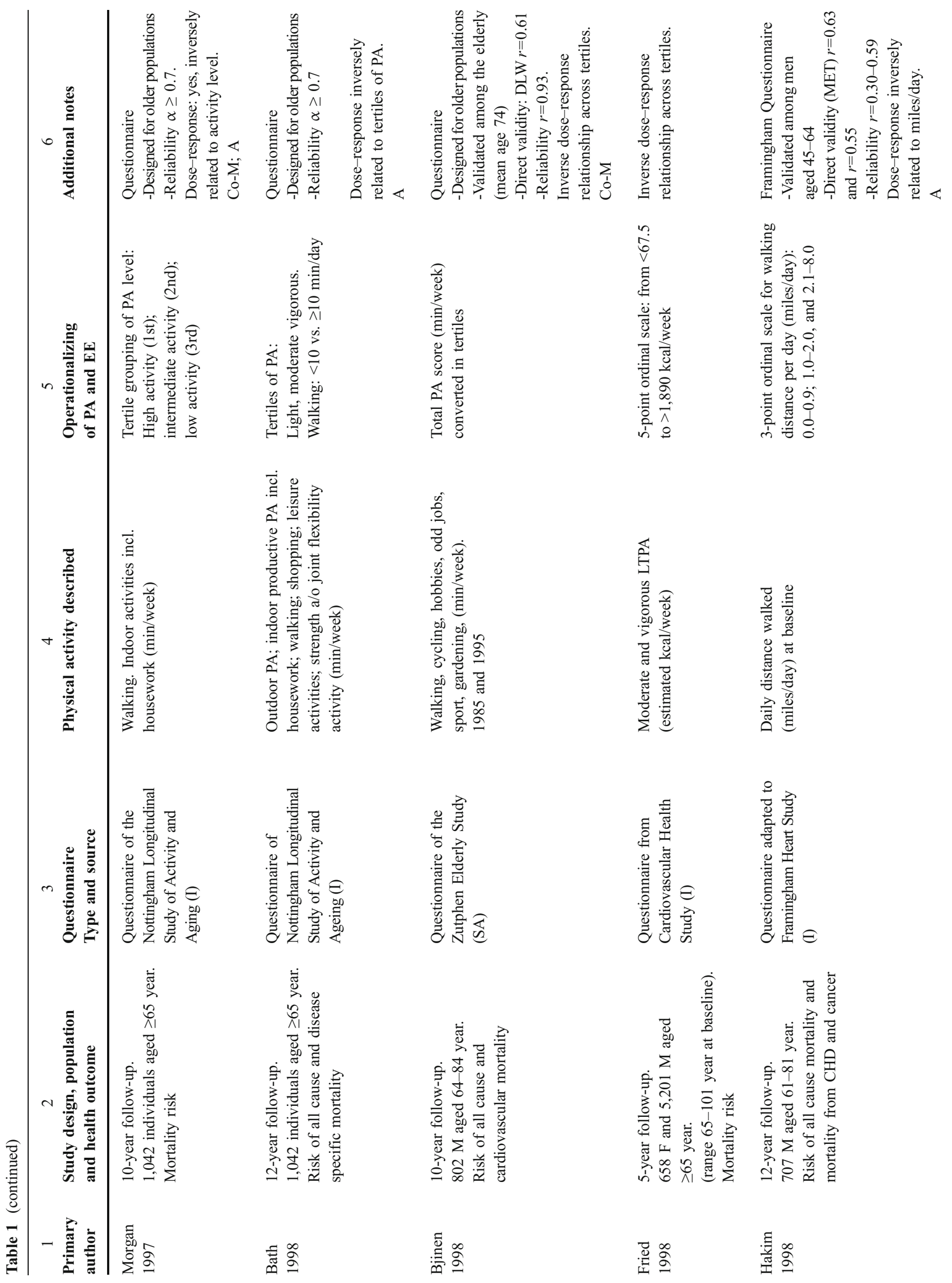




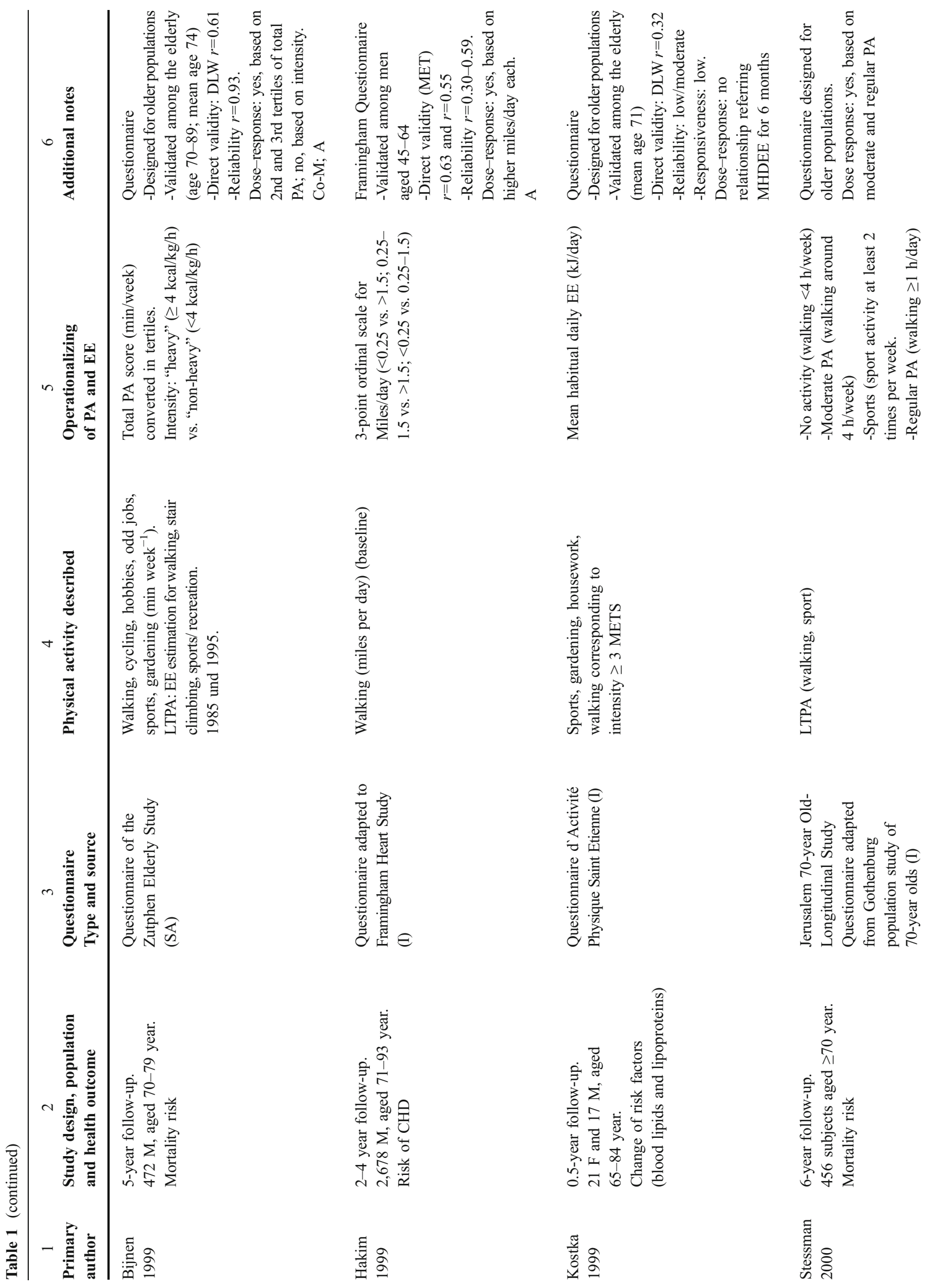




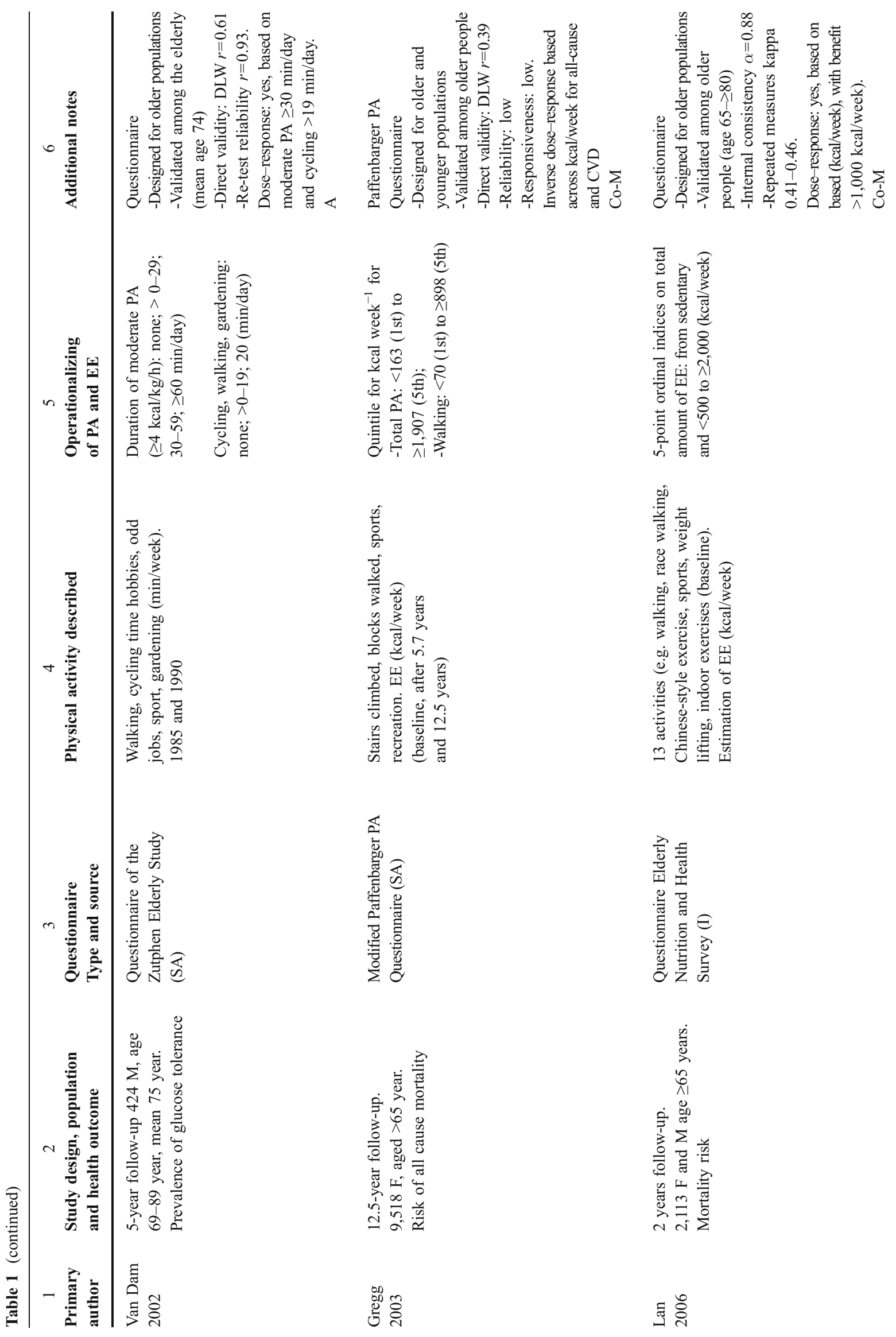


outcomes among older persons, with a wide range of dose-responses. The reviewed cohort studies suggested that none of the methods applied were entirely appropriate and sensitive enough to describe and measure both the PA behavior and related EE in the older population. Important methodological limitations were: a restricted use of available PA questionnaires specifically developed for and validated for the older population. The PA questionnaires used lacked appropriateness for age-specific features of PA. Although two instruments constructed for older populations are valid for assessing PA and reliable for estimating EE they do not cover the extremely diverse aspects of agespecific PA behavior and modes of muscular activity typical for the elderly. Only limited direct measurements of EE for PA in older adults had been undertaken. For the estimation of EE only non-age-specific tables had been used. These methodological deficiencies may limit the validity and interpretation of the dose-response relationships as reported in the epidemiologic studies reviewed.

Study limitations Facing these findings, the problem of a potential publication bias must be kept in mind. A literature review is highly selective in nature and may omit studies that have obtained what have been called "negative" results, which may not have reached publication.

Dose-response data leave us uncertain as to whether long-term observation, e.g. for 20 years, of PA and health outcomes confers different benefit when compared to short-term observation. To clarify and extend this issue, methodological advances in PA assessment are needed, i.e. additional observations on changes in PA over different time periods as they relate to health outcomes.

Implications for future research

To adequately assess health-relevant PA and EE for older populations in epidemiologic studies, questionnaires and methods should be designed which are more sensitive to the unstructured and complex PA common among the elderly [28]. To be most accurate, the sampling interval, the PA and EE units used, should be sensitive to both brief periods of activity and low-intensity activity. In order to allow meaningful dose-response interpretation there is a need for clearly defined and standardization, of the PA undertaken and EE units used for assessment in the elderly. Such age-specific measurements could also serve for the development of tables on EE appropriate for older people. Finally, it is suggested that epidemiological studies on health-enhancing PA and EE need to be reconsidered for appropriateness in the older population. The results of the dose-response relationship need to be interpreted with new findings and evidence. 
Acknowledgement We gratefully acknowledge the expert support of: Prof. Dr. Andreas Stuck, Dept of Geriatrics, University Hospital, Spital Ziegler, Bern, and Dr. Marcel Zwahlen, Institute for Social and Preventive Medicine, University of Bern, for reviewing the methodology of the studies. Dr Andros Tofield, medical writer, for his proofreading and recommendations for the English Language.

\section{References}

1. Ainsworth BE, Haskell WL, Leon AS, Jacobs DR, Montoye HJ, Sallis JF, Paffenbarger RS (1993) Compendium of physical activities: classification of energy costs of human physical activities. Med Sci Sports Exerc 25:71-80. doi:10.1249/ 00005768-199301000-00011

2. Ainsworth BE, Haskell WL, Whitt MC, Irwin ML, Swartz AM, Strath SJ, O'Brien WL, Bassett DR, Schmitz KH, Emplaincourt PO, Jacobs DR, Leon AS (2000) Compendium of physical activities: an update of activity codes and MET intensities. Med Sci Sports Exerc 32:S498-S516. doi:10.1097/00005768200009001-00009

3. Bath PA, Morgan K (1998) Customary physical activity and physical health outcomes in later life. Age Ageing 27(Suppl 3):29-34

4. Berk DR, Hubert HB, Fries JF (2006) Associations of changes in exercise level with subsequent disability among seniors: a 16-Year Longitudinal Study. J Gerontol 61A:97-102

5. Berthouze SE, Minaire PM, Chatard JC, Boutet C, Castells J, Lacour JR (1993) A new tool for evaluating energy expenditure: the «QAPSE» development and validation. Med Sci Sports Exerc 25:1505-1514. doi:10.1249/00005768-199312000-00015

6. Bijnen FC, Feskens EJ, Caspersen CJ, Giampaoli S, Nissinen AM, Mendotti A, Mosterd WL, Kromhout D (1996) Physical activity and cardiovascular risk factors among elderly men in Finland, Italy, and the Netherlands. Am J Epidemiol 143:553-561

7. Bijnen FC, Feskens EJ, Caspersen JC, Mosterd WL, Kromhout D (1998) Age, period, and cohort effects on physical activity among elderly men during 10 years of follow-up: the Zutphen Elderly Study. J Gerontol 53A:235-241

8. Bijnen FC, Feskens EJ, Caspersen CJ, Nagelkerke N, Mosterd WL, Kromhout D (1999) Baseline and previous physical activity in relation to mortality in elderly men: the Zutphen elderly study. Am J Epidemiol 150:1289-1296

9. Bonnefoy M, Normand S, Pachiaudi C, Lacour JR, Laville M, Kostka T (2001) Simultaneous validation often physical activity questionnaires in older men: a doubly labeled water study. J Am Geriatr Soc 49:28-35. doi:10.1046/j.1532-5415.2001.49006.x

10. Bouchard C, Rankinen $T$ (2001) Individual differences in response to regular physical activity. Med Sci Sports Exerc 33 (Suppl):S446-S451. doi:10.1097/00005768-200106001-00013

11. Caspersen CJ, Bloemberg BPM, Saris WHM, Merritt RK, Kromhout D (1991) The prevalence of selected physical activities and their relation with coronary heart disease in elderly men: the Zutphen study. Am J Epidemiol 33:1978-1992

12. Cumming RG, Klineberg RJ (1994) A study of the reproducibility of long-term recall in the elderly. Epidemiology 5:116-119. doi:10.1097/00001648-199401000-00017

13. Di Pietro L (2001) Physical activity in aging: changes in patterns and their relationship to health and function. J Gerontol 56A:13-33

14. Fried LP, Kronmal RA, Newman AB, Bild DE, Mittelmark MB, Polak JF, Robbins JA, Gardin JM (1998) Risk factors for 5-year mortality in older adults. JAMA 279:585-582. doi:10.1001/ jama.279.8.585

15. Gregg EW, Cauley JA, Stone K, Thompson TJ, Cummings SR, Ensrud KE (2003) Relationship of change in physical activity and mortality among older women. JAMA 289:2379-2386. doi:10.1001/jama.289.18.2379

16. Hakim AA, Petrovitch H, Burchfiel CM, Ross GW, Rodriguez BL, White LR, Yano K, Curb JD, Abbott RD (1998) Effects of walking on mortality among non-smoking retired men. N Engl J Med 338:94-99. doi:10.1056/NEJM199801083380204

17. Hakim AA, Curb JD, Petrovitch H, Rodriguez BL, Yano K, Ross W, White LR, Abbott RD (1999) Effects of walking on coronary heart disease in elderly men. The Honolulu Heart Program. Circulation 100:9-13

18. Kaplan GA, Seeman TE, Cohen RD, Knudsen LP, Guralnik J (1987) Mortality among the elderly in the Alameda County Study: behavioral and demographic risk factors. Journal of Public Health 77:307-312. doi:10.2105/AJPH.77.3.307

19. Kostka T, Lacour JR, Berthouze SE, Bonnefoy M (1999) Relationship of physical activity and fitness to lipid and lipoprotein (a) in elderly subjects. Med Sci Sports Exerc 31:1183-1189. doi:10.1097/00005768-199908000-00016

20. LaCroix AZ, Leveille SG, Hecht JA, Grothaus LC, Wagner EH (1996) Does walking decrease the risk of cardiovascular disease hospitalizations and death in older adults? J Am Geriatr Soc 44:113-120

21. Lan TY, Chang HY, Tai TY (2006) Relationship between components of leisure physical activity and mortality in Taiwanese older adults. Prev Med 43:36-41. doi:10.1016/j.ypmed.2006.03.016

22. Lawlor DA, Taylor M, Bedford C, Ebrahim S (2002) Is housework good for health? Levels of physical activity and factors associated with activity in elderly women. Results from the British Women's Heart and Health Study. J Epidemiol Community Health 56:473-478. doi:10.1136/jech.56.6.473

23. Lee DJ, Markides KS (1990) Activity and mortality among aged persons over an eight-year period. J Gerontol 45:39-42

24. Lee IM, Skerrett PJ (2001) Physical activity and all-cause mortality: what is the dose-response relation? Med Sci Sports Exerc 33(Suppl): S459-S471. doi:10.1097/00005768-200106001-00016

25. Manini MT, Everhart J, Patel K (2006) Daily activity energy expenditure and mortality among older adults. JAMA 296:171179. doi:10.1001/jama.296.2.171

26. Masse LC, Ainsworth BE, Tortolero S, Levin S, Fulton JE, Henderson KA, Mayo K (1998) Measuring physical activity in midlife, older, and minority women: issues from an expert panel. Journal Women's Health 7:57-67

27. Morgan K, Clarke D (1997) Customary physical activity and survival in later life: a study in Nottingham, UK. J Epidemiol Community Health 51:490-493. doi:10.1136/jech.51.5.490

28. Prohaska T, Belansky E, Belza B, Buchner D, Marshall V, McTigue K, Satariano W, Wilcox S (2006) Physical activity, public health, and aging: critical issues and research priorities. $\mathrm{J}$ Gerontol 61B:S267-S273

29. Rakowski W, Mor V (1992) The association of physical activity with mortality among older adults in the Longitudinal Study of Aging (1984-1988). J Gerontol 47:122-129

30. Reilly JJ, Penpraze V, Hislop J, Davies G, Grant S, Paton JY (2008) Objective measurement of physical activity and sedentary behaviour: review with new data. Arch Dis Child 93:614-619. doi:doi:10.1136/adc.2007.133272

31. Rothenberg EM, Bosaeus LG, Steen BC (2003) Energy expenditure at age 73 and 78 - a five year follow up. Acta Diabetol 40: S134-S138. doi:10.1007/s00592-003-0046-6 
32. Speakman JR (1998) The history and theory of the doubly labeled water technique. J Clin Nutr 68:932S-938S

33. Stessman J, Maaravi Y, Hammerman-Rozenberg R, Cohen A (2000) The effects of physical activity on mortality in the Jerusalem 70-YearOlds' Longitudinal Study. J Am Geriatr Soc 8:499-504

34. Troiano R, Berrigan D, Dood KW, Mâsse LC, Tilert T, McDowell M (2008) Physical activity in the United States measured by accelerometer. Med Sci Sports Exerc 40:181-188
35. Van Dam RM, Schuit AJ, Feskens EJ, Seidell JC, Kromhout D (2002) Physical activity and glucose tolerance in elderly men: the Zutphen elderly study. Med Sci Sports Exerc 34:1132-1136. doi:10.1097/00005768-200207000-00013

36. Van Pelt RE, Jones PP, Davy KP, Desouza CA, Tanaka H, Davy BA, Seals DR (1997) Regular exercise and the age-related decline in resting metabolic rate in women. J Clin Endocrinol Metab 82:32083212. doi:10.1210/jc. 82.10 .3208 